\title{
RESPONSABILIDADE CIVIL NA LGPD: PROBLEMAS E SOLUÇÕES
}

\author{
André Luis Mota Novakoski* \\ Samyra Haydêe Dal Farra Naspolini**
}

\begin{abstract}
RESUMO: Este estudo tem por objetivo analisar o sistema de responsabilidade civil de agentes de tratamento de dados pessoais instituído pela LGPD (Lei 13.709/18) apontando os principais problemas identificados pela literatura jurídica e suas possíveis soluções. O método de abordagem utilizado foi o hipotético dedutivo, baseado na literatura sobre o tema; o método de procedimento foi o hermenêutico e a técnica de pesquisa, bibliográfica.
\end{abstract}

Palavras-chave: LGDP; Dados pessoais; Responsabilidade civil; Perdas e danos; Sociedade da informação.

\section{LIABILITY IN LGPD: PROBLEMS AND SOLUTIONS}

ABSTRACT: This study aims to analyze the civil liability system for personal data processing agents established by the LGPD (13.709/18 Act) pointing out the main problems identified by the legal literature and its possible solutions. The method of approach used was the deductive hypothetical, based on the doctrine on the issue; the procedure method was hermeneutic and the research technique was bibliographic.

Keywords: LGDP; Personal data; Liability; Losses and damages; Information society.

\section{Introdução}

O problema enfrentado pelo presente artigo refere-se a um dos mais relevantes debates atuais em torno da Lei 13.709/18, a Lei Geral de Proteção de Dados - LGPD, que é: qual a responsabilidade civil dos agentes de tratamento de dados privados? Seria objetiva ou subjetiva? Isso porque a lei não dispôs, de forma expressa e precisa, sobre a necessidade (ou

\footnotetext{
* Mestrando em Direito da Sociedade da Informação pelo Centro Universitário das Faculdades Metropolitanas Unidas (FMU-SP). Especialista em Direito Ambiental pela Universidade de São Paulo (USP) e em Direito Processual Civil pela Pontifícia Universidade Católica de São Paulo (PUC-SP). Contato: Rua Funchal 411, 5 andar, Delta Business Center, Vila Olimpia, São Paulo, SP, CEP 04551-060, e-mail: andre@nvkk.com.br. Lattes: http://lattes.cnpq.br/9359747942711767. Orcid: https://orcid.org/0000-0003-0985-3053.

** Doutora em Direito pela Pontifícia Universidade Católica de São Paulo (PUC-SP). Mestre em Direito pela Universidade Federal de Santa Catarina (UFSC). Docente e pesquisadora e professora permanente do Programa de Mestrado em Direito na Sociedade da Informação e do Curso de Graduação em Direito do Centro Universitário das Faculdades Metropolitanas Unidas (FMU-SP). Docente e pesquisadora permanente do Mestrado em Direito do Centro Universitário de Marília (UNIVEM). Editora da Revista Em Tempo (UNIVEM). Membro associado e Diretora Executiva do Conselho de Pesquisa e Pós Graduação em Direito (CONPEDI) e da Associação Brasileira de Ensino do Direito (ABEDi). Contato: Rua Vergueiro, 749, Liberdade, São Paulo, SP, CEP 01504-001, e-mail: samyranaspolini@gmail.com. Lattes: http://lattes.cnpq.br/4529730931640744. Orcid: https://orcid.org/0000-0002-1838-9005. 
não) de culpabilidade para caracterização da obrigação de indenizar, tema objeto de investigação neste estudo.

A sociedade contemporânea é caracterizada, dentre outros elementos, pelo incessante fluxo de informações e criação de comunidades por meio da internet (a "sociedade red" de Manuel Castells) ${ }^{1}$ e a produção de riscos em escala industrial (a "Risikgesellschaft" de que trata Ulrich Beck). ${ }^{2}$

O risco de lesão a direitos no tráfego de dados pessoais é uma realidade como evidenciam as corriqueiras notícias de vazamento de informações pessoais sensíveis - a ponto de terem dado motivo à criação da jocosa expressão "another day, another leak" - e a sociedade tem se preocupado cada vez mais com a questão, especialmente após a ampliação do uso de algoritmos, learning machines, deep learning, data tracking e outras ferramentas de inteligência artificial para coleta e tratamento de dados obtidos no ciberespaço.

Partindo da premissa de que a legislação existente não seria suficiente para resolver os desafios emergentes deste novo cenário, a LGPD (Lei 13.709/18) instituiu um regime de responsabilidade civil próprio para situações envolvendo lesões ocorridas no tratamento de dados pessoais. Porém, não se pode ignorar a coerência interna do sistema de responsabilidade civil no direito brasileiro e todo a trajetória do instituto ao longo do Século XX.

O objetivo, portanto, da presente pesquisa é investigar se a LGPD exige prova da culpa para a caracterização do dever de indenizar por violação dos princípios e regras de proteção de dados pessoais instituídas pela LGPD. Para alcançar seu objetivo o artigo foi dividido em três itens, no primeiro será estudada a privacidade e autodeterminação informativa no ordenamento jurídico brasileiro, no segundo item será investigada a responsabilidade civil por lesão a dados pessoais na LGPD, e no quarto e último item

\footnotetext{
${ }^{1}$ Explica Manuel Castells que "las redes on line pueden construir comunidades, o sea comunidades virtuales, diferentes de las comunidades físicas pero no necesariamente menos intensas o menos efectivas a la hora de unir y movilizar. Es más, lo que observamos en nuestras sociedades es el desarrollo de un hibrido de comunicación en el que se juntan el lugar físico y el ciberlugar (por usar la terminología de Wellman), actuando como soporte material del individualismo en red." (CASTELS, 2001, p. 152)

${ }^{2}$ A pergunta nuclear sobre os destinos da responsabilidade civil do Século XXI foi formulada por Ulrich Beck: "Como é possível que as ameaças e os riscos sistematicamente coproduzidos no processo tardio de modernização sejam evitados, minimizados, dramatizados, canalizados e, quando vindos à luz sob a forma de 'efeitos colaterais latentes', isolados e redistribuídos de modo tal que não comprometam o processo de modernização e nem as fronteiras do que é (ecológica, medicinal, psicologicamente ou socialmente) 'aceitável'?". (BECK, 2011, p. 24)
} 
realizaremos uma análise crítica sobre essas disposições da LGDP sobre responsabilidade civil.

\section{Privacidade e autodeterminação informativa}

Embora o direito humano à privacidade tenha sido reconhecido pela sociedade e incluído na maior parte dos textos constitucionais do Ocidente, principalmente após a seminal contribuição de Louis Brandeis e Samuel Warren (1890, p. 193-220), há relativo consenso na literatura jurídica estrangeira (POSNER, 1978, p. 393; SOLOVE, 2006, p. 477) e brasileira (FILKENSTEIN; FINKELSTEIN, 2019, p. 286-287) admitindo a fluidez e consequente dificuldade de definição de um conceito rígido para o instituto.

Se esta dificuldade é evidente no mundo físico, concreto, é ainda mais inegável no ambiente do ciberespaço, onde a evolução da internet e suas infinitas aplicações tem evidenciado cada vez mais a dissociação entre real e virtual, como advertiu John Perry Barlow (2019, p. 5-7).

Os dados pessoais representam, hoje, a "última fronteira" do direito privado.

Contudo, apesar de sua relevância, a legislação e a jurisprudência vinham encontrando dificuldade em evoluir tão rapidamente quanto a tecnologia e o uso de dados pessoais, gerando situações de tensão que exigiram a intervenção (a bem ou mal) do legislador.

Influenciado pela experiência estrangeira, especialmente a General Data Protection Regulation (GDPR) europeia (ERICKSON, 2019, p. 861-863) e seguindo a técnica legislativa de diplomas especiais regulando setores sociais e econômicos de forma particular e especializada, consolidada ao longo no Século XX (MORAIS, 2019, p. 1), o legislador brasileiro promulgou a Lei Geral de Proteção de Danos (LGPD).

A LGPD busca, dentro do filtro do direito infraconstitucional, a concretização do direito fundamental à privacidade, assegurando instrumentos para proteção material e processual da autodeterminação informativa (BARRETO JÚNIOR; NASPOLINI, 2019, p. 
142), compreendido como o direito de a pessoa poder controlar eficazmente a divulgação e uso de suas informações por terceiros:

A denominada privacidade contextual é um direito da personalidade, desdobramento do direito à privacidade e do direito à intimidade, conferindo-se ao seu titular, em tempos de sociedade da informação, o exercício de sua autodeterminação informacional.

Assim, o titular dos dados pessoais possui controle efetivo e contínuo a respeito do fluxo informacional (LISBOA, 2019, p. 11)

Embora este incluído no âmbito da privacidade em sentido amplo, o direito à autodeterminação informativa dele difere, gozando de status de autonomia propedêutica, em razão de sua característica dinâmica, fluída (BARRETO JÚNIOR; NASPOLINI, 2019, p. 142).

Em razão da importância do domínio da pessoa sobre seus dados pessoais, a LGPD instituiu um sistema de alta carga principiológica, com especial relevo ao consentimento, exigindo-o de forma específica e, principalmente, autorizando à pessoa sua revogação de forma potestativa (art. $8^{\circ}, \S 5^{\circ}$, LGPD):

Entende-se que o sistema desenvolvido tem como pilares centrais: a) amplo conceito de dado pessoal; b) necessidade de que qualquer tratamento de dados tenha uma base legal; c) rol taxativo de hipóteses legais para o tratamento de dados; d) caracterização detalhada do consentimento do titular e preocupação com sua manifestação; e) legítimo interesse como uma das hipóteses autorizativas e necessidade de realização de um teste de balanceamento de interesses para a sua regular aplicação; f) amplo rol de direitos do titular; e g) densa carga principiológica. (TEFFÉ; VIOLA, 2020, p. 38)

Uma vez em posse (legítima e consentida) dos dados pessoais gerais ou sensíveis (art. 5', I e II, LGPD), o controlador ou operador do banco de dados poderá tratá-los livremente (art. 5, X, LGPD), observando os princípios e limites estabelecidos pela legislação e regulação oriunda da autoridade nacional de proteção de dados (ANPD) (art. $6^{\circ}$, I a X; art. 46, LGPD), sob pena de incorrer em responsabilidade civil. 


\section{Responsabilidade civil por lesão a dados pessoais na LGDP}

Embora a LGPD tenha estabelecido um conjunto de princípios e regras que procuram criar um ambiente de responsabilidade proativa, de cunho preventivo, o risco potencial de ocorrência de lesão na coleta e tratamento de dados pessoais, especialmente ante os riscos inerentes à uma sociedade de classificação (FRAZÃO, 2019, p. 35), reclama um sistema de responsabilidade civil apto a propiciar a efetiva tutela da vítima e a reparação integral do dano.

Com o escopo de fornecer bases para estas situações de lesão imprevista e inevitável, a LGPD dedicou um capítulo para a regulação da responsabilidade civil dos agentes no âmbito de danos causados pelo tratamento de dados pessoais, distribuídos entre os arts. 42 a 45 da lei.

O art. 42 da LGPD contém uma cláusula geral de responsabilidade, imputando a obrigação de indenizar ao controlador ou operador que, descumprindo a legislação de proteção de dados, causar dano patrimonial ou extrapatrimonial aos titulares dos dados pessoais violados:

Art. 42. O controlador ou o operador que, em razão do exercício de atividade de tratamento de dados pessoais, causar a outrem dano patrimonial, moral, individual ou coletivo, em violação à legislação de proteção de dados pessoais, é obrigado a repará-lo.

De forma similar ao regime implantado pelo Código de Defesa do Consumidor CDC (Lei 8.078/90), a LGPD estabeleceu a solidariedade dos agentes que causaram a lesão (art. 42, § $1^{\circ}$, I e II) e, para mitigar a assimetria na relação entre controladores, operadores e titulares de dados pessoais, permitiu a inversão do ônus da prova por critério judicial (art. 42, $\S 2^{\circ}$ ), o que, a rigor cientifico, implica um sistema de presunção legal do dano sofrido pela vítima lesada:

Não existe propriamente uma inversão do ônus dos encargos probatórios quando o juiz aplica o art. $6^{\circ}$, VIII, do CDC. [...] Ao contrário, o que verdadeiramente ocorre quando se aplica o art. $6^{\circ}$, VIII, do CDC é que o juiz passa a presumir que os fatos ocorreram de acordo com a narrativa do autor consumidor (presunção juris tantum), de modo que o réu fornecedor 
conserva os mesmíssimos ônus probatórios que possuía antes da "inversão" (art. 333, II, do CPC), permanecendo com a necessidade de fazer prova de que os fatos descritos na petição inicial não ocorreram ou ocorreram de forma diversa do alegado pelo consumidor, podendo comprovar, ainda, a existência de fatos impeditivos, modificativos ou extintivos do direito afirmado pelo consumidor. (NOVAKOSKI, 2006, p. 10-11)

No dispositivo seguinte, a LGPD trata das hipóteses de exceção da responsabilidade dos agentes de tratamento, quando provarem que i) não realizaram o tratamento dos dados pessoais, ii) se o realizaram, não violaram as normas de proteção de dados pessoais ou iii) que o dano foi causado por terceiro ou pelo próprio titular (art. 43, I a III).

Art. 43. Os agentes de tratamento só não serão responsabilizados quando provarem:

I - que não realizaram o tratamento de dados pessoais que lhes é atribuído;

II - que, embora tenham realizado o tratamento de dados pessoais que lhes é atribuído, não houve violação à legislação de proteção de dados; ou

III - que o dano é decorrente de culpa exclusiva do titular dos dados ou de terceiro.

O art. 44 da LGPD define o conceito de tratamento irregular de dados.

À semelhança da disciplina adotada pelo CDC, a LGPD estabeleceu que o tratamento de dados será irregular quando contrariar a disciplina legal (art. 44, caput) ou, também, quando não fornecer a segurança legitimamente esperada pelo respectivo titular (art. 44, I a III):

Art. 44. O tratamento de dados pessoais será irregular quando deixar de observar a legislação ou quando não fornecer a segurança que o titular dele pode esperar, consideradas as circunstâncias relevantes, entre as quais:

I - o modo pelo qual é realizado;

II - o resultado e os riscos que razoavelmente dele se esperam;

III - as técnicas de tratamento de dados pessoais disponíveis à época em que foi realizado.

Diferentemente dos dispositivos anteriores, que regulam a responsabilidade por violação de normas jurídicas do microssistema de proteção de dados pessoais, o $\S$ único do art. 44 da LGPD estabelece o dever de indenizar derivado da violação de normas técnicas oriundas da autoridade nacional de proteção de dados (ANPD): 
Art. 44. [...]

Parágrafo único. Responde pelos danos decorrentes da violação da segurança dos dados o controlador ou o operador que, ao deixar de adotar as medidas de segurança previstas no art. 46 desta Lei, der causa ao dano.

...

Art. 46. Os agentes de tratamento devem adotar medidas de segurança, técnicas e administrativas aptas a proteger os dados pessoais de acessos não autorizados e de situações acidentais ou ilícitas de destruição, perda, alteração, comunicação ou qualquer forma de tratamento inadequado ou ilícito.

O art. 45 da LGPD, último da Seção III da lei, ressalva que as situações de lesão a direito de consumidor ou pessoa a ele equiparada continuam sujeitas à disciplina do microssistema de relações de consumo instituído pelo CDC (Lei 8.078/90).

\section{Análise crítica das disposições da LGDP sobre responsabilidade civil}

Antes de apresentar as duas linhas que se formaram a respeito do tema, é necessário ponderar que a proliferação de microssistemas jurídicos, tendência legislativa consolidada desde o final do Século XX e que tem se intensificado nas relações entre direito e internet, tem um grave inconveniente, que é uma erosão da sistematicidade e unidade do sistema jurídico de direito privado, como observado por Gustavo Tepedino e Rodrigo da Guia Silva:

Tais linhas teóricas compartilham o esforço de definição das soluções mais adequadas aos novos problemas. Identificam-se, nesse sentido, variadas formulações que enunciam princípios éticos próprios para a regulação dos robôs e demais sistemas autônomos. As célebres Leis de Asimov servem como boa representação do quanto exposto: o temor (ou encanto) das novidades tecnológicas parece instigar a formulação de novas regras e novas soluções. Empreende-se, assim, grande esforço para a concepção de respostas que se possam reputar adequadas aos novos desafios suscitados pela inteligência artificial. (TEPEDINO; SILVA, 2019, p. 70)

Lembrando que o ordenamento jurídico, segundo a dogmática jurídica, caracteriza-se por um conjunto de normas que formam um sistema completo e coerente, essa coerência significa que não pode existir contradição entre as normas jurídicas que o compõem. 
A situação de normas incompatíveis entre si dentro de um mesmo ordenamento é uma dificuldade corrente, à qual se defrontam os aplicadores do Direito de todos os tempos, principalmente quando surgem novos ramos do direito.

A rigor, a enunciação de novo ramo do direito voltado especificamente para as questões da robótica e da inteligência artificial traz consigo o grave risco de tratamento assistemático da matéria. Os fundamentos para a tutela das vítimas de danos injustos não devem ser buscados em novos e esparsos diplomas normativos, mas sim - e sempre - no ordenamento jurídico em sua unidade e complexidade. A disciplina ordinária da responsabilidade civil tanto em relações paritárias quanto em relações de consumo -, embasada na tábua axiológica constitucional, serve de fundamento suficiente para o equacionamento dos problemas referentes aos danos causados por sistemas autônomos. Advirta-se, por oportuno: o tratamento sistemático ora propugnado deve levar em consideração o ordenamento jurídico em sua unidade e complexidade, sem se cair na armadilha da enunciação de um (mais um chamado micro) sistema próprio de valores da lex robotica. (TEPEDINO; SILVA, 2019, p. 70-71)

Outro problema quando se enuncia um novo ramo do direito diz respeito à completude do ordenamento. "Por completude entende-se a propriedade pela qual um ordenamento jurídico tem uma norma para regular qualquer caso. Uma vez que a falta de uma norma se chama geralmente lacuna, (...) completude significa falta de lacunas.” (BOBBIO, 1982, p. 113).

Segundo Claus-Wilhelm Canaris:

De fato a formação de um sistema completo numa determinada ordem jurídica permanece sempre um objetivo não totalmente alcançado. Opõe-selhe invencivelmente, a natureza do Direito (...) uma determinada ordem jurídica positiva não é uma 'ratio scripta', mas sim um conjunto historicamente formado, criado por pessoas, apresentando como tal, de modo necessário, contradições e incompletudes, inconciliáveis com o ideal da unidade interior e da adequação e, assim com o pensamento sistemático. (...)'Quebras no sistema' e 'lacunas no sistema' são, por isso, inevitáveis. (CANARIS, 1996, p 199-200)

Portanto, o nexo entre coerência e completude está em que a coerência significa a exclusão de toda a situação na qual pertençam ao sistema ambas as normas que se contradizem; a completude significa a exclusão de toda a situação na qual não pertençam ao 
sistema nenhuma das duas normas que se contradizem. Diremos incoerente um sistema no qual existem tanto a norma que proíbe um certo comportamento quanto aquela que o permite; incompleto é um sistema no qual não existem nem a norma que proíbe um certo comportamento nem aquela que o permite:

\begin{abstract}
Nesse contexto, a enunciação de supostos vazios normativos representa problema muito mais grave do que o mero abalo à dogmática consolidada na tradição jurídica. Com efeito, ao afrontar a unidade e a completude do ordenamento, a indicação insistente de lacunas finda por comprometer a própria efetividade da tutela prometida às vítimas de danos injustos, como se das suas necessidades não desse conta o sistema ora vigente. Em vez de buscar - muitas vezes irrefletida - novas soluções e novos diplomas legais, melhores resultados se haverão de alcançar pelo esforço de releitura dos institutos já conhecidos pela civilística. (TEPEDINO; SILVA, 2019, p. 71)
\end{abstract}

Logo, a análise da disciplina da LGPD não pode dispensar toda a evolução do sistema de responsabilidade civil legado pelo direito privado, principalmente das normas do Código Civil e pelo CDC, que, por sua alta carga principiológica, valorativa e posição topológica no ordenamento (COSTA NETO, 2018, p. 63), ${ }^{3}$ viabilizam a contínua construção e reconstrução da interpretação dos institutos de direito privado funcionalizando-os para atender às necessidades empíricas de uma sociedade em constante mutação, massificada, globalizada e de alta complexidade, assegurando o prestígio ao caráter ético que deve permear a conduta humana e as relações sociais (FACHIN, 1998, p. 146).

A partir do exame dos arts. 42 a 45 da LGDP, surgiram duas linhas de interpretação sobre a natureza da responsabilidade civil dos agentes de tratamento de dados pessoais: para parte da doutrina a responsabilidade civil envolvendo o tratamento de dados pessoais seria subjetiva, enquanto a posição divergente entende que a LGPD teria se filiado ao sistema do risco e, portanto, objetiva:

Deve-se o fato à aparente imprecisão normativa quanto ao sistema de responsabilidade civil adotado pela lei protetiva. O embate doutrinário é travado entre posições que afirmam ter a lei estabelecido um sistema

\footnotetext{
${ }^{3}$ Sobre este ponto específico, Moacyr da Costa Neto defende que "o Código Civil adotou, em diversas passagens a técnica de utilização de normas jurídicas de grande amplitude semântica, conferindo ao Estado-Juiz a tarefa de preencher casuisticamente seu significado, delimitando sua eficácia e alcance, conferindo a tal diploma maior mobilidade, porquanto prolongando a aplicabilidade dos institutos jurídicos, orientados pela regência dos direitos e garantias fundamentais consagrados na Constituição da República”. (COSTA NETO, 2018, p. 63)
} 
baseado na responsabilidade objetiva ou subjetiva, sendo respeitáveis os posicionamentos em ambos os sentidos. (TASSO, 2020, p. 104)

Ambas as correntes possuem uma premissa comum, que é o argumento de que a LGPD padeceria de grave "inexatidão terminológica” (TASSO, 2020, p. 104), pois o enunciado do art. 42 não teria sido suficientemente claro quanto ao regime de responsabilidade civil — subjetivo ou objetivo - adotado pela norma (CAPANEMA, 2020, p. 165-167).

A despeito das opiniões que sustentam que o tratamento de dados pessoais seria inofensivo e não representaria qualquer risco aos envolvidos, principal argumento em favor da responsabilidade subjetiva, a redação do art. 42 da LGDP não permite esta conclusão.

Por mais zeloso que seja o agente, nenhuma atividade humana é livre de riscos (DEVLIN, 2015, p. 99), devendo o direito fixar regras que permitam alocá-los adequadamente:

Se os riscos são probabilidades de ganhos ou perdas, quanto a estas, é preciso modelar instrumentos que permitam transferir ou mitigá-las. (STAJN, 2011, p. 8)

Frente a esta realidade inequívoca, o direito contemporâneo tem regulado o instituto da responsabilidade civil no sentido de eliminar o denominado "custo social da nãoreparação" de danos injustos, que se constitui em um fenômeno erosivo da segurança jurídica e fonte de injustiça que as mais diversas teorias jurídicas aplicadas ao direito privado, como a análise econômica do direito e constitucionalização do direito civil, não toleram (SCHREIBER, 2009, p. 220-221).

É lição velha de hermenêutica que a lei não contém disposições inúteis (a despeito da baixa qualidade do poder legislativo).

Neste sentido, a expressão "em razão do exercício de atividade de tratamento de dados pessoais" incluída no art. 42 da LGPD não pode ser privada de sentido, como sugerem os defensores da teoria subjetivista.

$\mathrm{O}$ art. 42 da LGPD reconhece, naquela expressão e ainda que de forma implícita, que a atividade de tratamento de dados pessoais envolve risco potenciais, os quais, registre-se, são CONPEDI LAW REVIEW | EVENTO VIRTUAL | v. 6 | n. 1 | p. 158 - 174 | JAN - DEZ | 2020 
explicitamente admitidos, em maior ou menor grau, em diversos outros dispositivos da norma (art. 5 XVII; art. 38, §́nico; art. 44, II; art. 48, caput c/c $\S 1^{\circ}$, IV; art. 50, caput c/c $\S 1^{\circ}$; art. $55, \mathrm{XIII})$.

Sendo o Código Civil a fonte última irradiadora de princípios e regras de direito privado, a interpretação do art. 42 da LGPD deve ser realizada de forma coerente e sistemática ao disposto no art. 927, § único, do Código Civil, que adotou a teoria da responsabilidade objetiva fundada no risco da atividade exercida pelo agente da atividade potencialmente lesiva, eliminando a situação de socialização do prejuízo na qual a vítima era forçada a suportar o dano em razão da dificuldade (prática, financeira, probatória) de provar a culpa:

Já denominada prova diabólica diante das dificuldades que trazia, no século XIX, às vítimas de danos derivados do maquinismo industrial, a prova da culpa veio gradativamente perdendo relevância em todos os ordenamentos de civil law. Assistiu-se, embora não necessariamente em uma evolução linear, (i) à multiplicação das presunções de culpa; (ii) ao avanço da responsabilidade fundada no risco; e (iii) à alteração da própria noção de culpa e do modo de sua aferição. (LEMINSKI, 2013, p. 153-4)

Não faria sentido a LGPD ter criado um sistema de proteção de dados pessoais se, na concretização deste sistema, ele fosse débil ou factualmente inútil, propiciando uma situação de perpetuação do estado de lesão a um direito de personalidade (BARRETO JÚNIOR; CAVALCANTI; LEITE, 2018, p. 523).

Aponta-se ainda que o art. 43 da LGPD evidenciaria que a responsabilidade civil prevista na norma teria cunho subjetivo por envolveria a necessidade de demonstração de culpa do agente de tratamento de dados pessoais, o que não é verdadeiro.

As hipóteses descritas nos incisos I a III do art. 43 da LGPD não guardam qualquer vínculo com a exigência de culpa, mas se relacionam a hipóteses de ruptura do nexo de causalidade.

$\mathrm{O}$ art. 44 da LGPD, por sua vez, impõe padrões comportamentais ao agente de tratamento de dados pessoais, ou seja, estabelece deveres de resultado (e não se simples diligência), cujo descumprimento implica, per se, a responsabilização do causador do dano independentemente de prova de culpa 
Um óbice usualmente levantado pelos defensores da tese da responsabilidade civil subjetiva da LGPD se escorra no fato de que a adoção da teoria do risco da atividade inibiria a competição e o desenvolvimento de novas tecnologias.

A afirmação, que parece ter um tom de novidade, foi exaustivamente examinada quando da promulgação do CDC e do próprio Código Civil em vigor; ao contrário dos partidários da tese, a imputação da responsabilidade objetiva nas hipóteses estabelecidas nestes diplomas não inibiu a inovação e o desenvolvimento de novas tecnologias, mas certamente as tornou mais seguras e impediu a socialização dos riscos de desenvolvimento (e dos danos a eles relacionados), imputando o dever de reparar àquele que exerce a atividade e assegurando a efetiva proteção das vítimas de danos injustos, a ponto de não surpreender a descoberta (ou desenvolvimento) de um "princípio da proteção da vítima" na interpretação do sistema civil-constitucional vigente:

Cuida-se, porém, de falso dilema, pois a história já demonstrou que a adoção dos modelos de culpa presumida ou de responsabilidade objetiva, que flexibilizaram a dificuldade da prova da culpa, não limitaram o desenvolvimento de novas tecnologias. Ao contrário: assegurou-se o pleno desenvolvimento tecnológico e industrial e os custos dos modelos de responsabilização objetivos, em especial nas relações de consumo, foram incorporados pelo mercado sem prejuízo do ressarcimento das vítimas de danos injustos, implementando-se o modelo solidarista de responsabilidade fundado na atenção e no cuidado para com o lesado. Ademais, já pontuava Rodotà, o argumento de eventual aumento dos custos de proteção dos dados pessoais para as empresas não é decisivo, vez que não se pode considerar que interesses ligados à proteção de dados pessoais dos titulares sejam de status inferior aos interesses empresariais. (MORAES, 2019, p. 4)

Uma breve consideração sobre responsabilidade em sentido amplo no âmbito da LGPD parece ser relevante.

Maria Celina Bodin de Moraes denomina o modelo de responsabilidade lato sensu adotado pela LGPD como "proativo", baseado em um sistema de prestação de contas (“accountability”), no qual o eixo axiológico do instituto se deslocaria da reparação do dano para sua prevenção de forma eficaz:

Trata-se do conceito de "prestação de contas". Esse novo sistema de responsabilidade, que vem sendo chamado de "responsabilização ativa" ou 
"proativa", encontra-se indicado no inciso $\mathrm{X}$ do art. $6^{\circ}$, que determina às empresas não ser suficiente cumprir os artigos da lei; será necessário também "demonstrar a adoção de medidas eficazes e capazes de comprovar a observância e o cumprimento das normas de proteção de dados pessoais e, inclusive, a eficácia dessas medidas". Portanto, não descumprir a lei não é mais suficiente; é preciso "proativamente" prevenir a ocorrência de danos (MORAES, 2019, p. 5)

A ponderação de Moraes decorre da natureza multidisciplinar e transversal que o instituto da responsabilidade tem assumindo no Século XXI, no qual seu campo de função deixa de ser apenas reparatória (ou seja, estritamente jurídica) e passa a incidir antecipadamente (preventiva em sentido lato, logo ética), instituindo mecanismos para impedir a causação do dano, denominada responsabilidade preventiva (LOPES, 2010, p. 1230).

Sopesando estas premissas, parece ser um contrassenso a legislação dispor sobre mecanismos de responsabilidade preventiva, tendentes a impedir a causação do dano, e simultânea —e, nos parece, contraditoriamente— subordinar a reparação de danos decorrentes de lesão a dados pessoais, que são um direito humano básico, ao regime da responsabilidade civil subjetiva, com todas as dificuldades a ele inerentes, e que, desde o debate de Saleilles e Josserand, ainda no final do Século XIX, permitiu a paulatina transformação da responsabilidade civil aquiliana em objetiva por meio de mecanismos como a culpa presumida e as teorias do risco.

Seria contraditório, ainda, que a LGPD permitisse que a responsabilidade civil decorrente de um mesmo fato objetivamente considerado - violação de normas de proteção de dados pessoais - pudesse ter tratamento diferenciado conforme a natureza do agente envolvido, isto é, subjetiva para agentes de direito privado e objetiva para entes de direito público, dado que, não tendo regulado explicitamente a responsabilidade civil destes últimos, a respectiva responsabilidade civil forçosamente observará a teoria do risco administrativo (art. 37, $\S 6^{\circ}, \mathrm{CF} / 88$ ), logo, será objetiva para os atos comissivos e subjetiva para os omissivos:

Contrariamente, ao não tratar especificamente da responsabilidade civil dos entes públicos quando da verificação de danos decorrentes de tratamento de dados pessoais, a Lei deixou ao intérprete a tarefa de proceder à integração do sistema protetivo. 
Não parece haver dúvidas que, nesta hipótese, a responsabilidade civil do ente público se dá com fundamento na teoria do risco administrativo.

$\cdots$

Dessa forma, segundo o entendimento do Supremo Tribunal Federal, a responsabilidade estatal no espectro das atividades de tratamento de dados pessoais é analisada segundo os critérios da responsabilidade objetiva para os atos comissivos, aqui exemplificados como o tratamento e o compartilhamento irregular de dados e, por outro lado, segundo os pressupostos da responsabilidade subjetiva em se tratando de ato omissivo, como, por exemplo, a não observância das normas de prevenção e de segurança da informação a oportunizar o vazamento de dados pessoais dos cidadãos. (TASSO, 2020, p. 105)

Por último e não menos importante, a suposta dubiedade do sistema de responsabilidade civil adotado pela LGPD —que este estudo procurou demonstrar não existir - não pode servir de fundamento à adoção da teoria da culpa, que dificulta o acesso da vítima à justiça e a afasta da reparação do dano, dado que, sendo dados pessoais um atributo do direito humano fundamental de personalidade, o art. 29 da Convenção Interamericana de Direitos Humanos, da qual o Brasil é signatário, exige que a interpretação das regras jurídicas envolvendo direitos humanos priorize a norma mais favorável à pessoa humana, aspecto que é usualmente desconsiderado pelos adeptos da teoria subjetiva da responsabilidade civil prevista na LGPD.

\section{Conclusão}

A responsabilidade civil contemporânea, fundada nos princípios de equilíbrio na distribuição dos riscos, na equidade no tratamento dos agentes e das vítimas e, não menos importante, no ideal de solidariedade social, concentra suas preocupações na reparação do dano injusto causado à vítima, o que se mostra essencial na sociedade da informação e do risco.

A exigência de prova da culpa para a caracterização do dever de indenizar por violação dos princípios e regras de proteção de dados pessoais instituídas pela LGPD, a despeito de ponderáveis argumentos, ignora a coerência interna do sistema de 
responsabilidade civil no direito brasileiro e todo a trajetória do instituto ao longo do Século XX e sua transição da teoria da culpa para a do risco da atividade.

A atividade de tratamento de dados pessoais, por envolver um atributo do direito de personalidade do titular, apresenta riscos potenciais, que são explicitamente mencionados pela LGPD, cuja interpretação sistemática evidencia a adoção da teoria da responsabilidade civil objetiva, decorrente da violação das obrigações de resultado previstas na lei, que somente pode ser excepcionada nas hipóteses de ruptura do nexo causal reguladas na própria LGPD.

\section{Referências}

BARLOW, John Perry. A declaration of the independence of cyberspace. Duke Law \& Technology Review, vol. 18, n. 1, Durham, 2019, p. 5-7. Disponível em: https://scholarship.law.duke.edu/dltr/vol18/iss1/2. Acesso em 10 jun. 2020.

BARRETO JUNIOR, Irineu Francisco; NASPOLINI, Samyra Haydêe Dal Farra. Proteção de informações no mundo virtual: a LGPD e a determinação de consentimento do titular para tratamento de dados pessoais. Cadernos Adenauer: Proteção de dados pessoais: privacidade versus avanço tecnológico, ano XX, n. 3, Rio de Janeiro: Fundação Konrad Adenauer, out. 2019. p. 137-155.

BARRETO JUNIOR, Irineu Francisco; WANDERLEY, Ana Elizabeth Lapa; LEITE, Beatriz Salles Ferreira. Sistemas de responsabilidade civil dos provedores de aplicações da internet por ato de terceiros: Brasil, União Europeia e Estados Unidos da América. Revista Eletrônica do Curso de Direito da UFSM, v. 13, n. 2, Santa Maria, ago. 2018. p. 506-531. Disponível em: https://periodicos.ufsm.br/revistadireito/article/view/28622. Acesso: 27 jun 2020.

BECK, Ulrich. Sociedade de risco: rumo a uma outra modernidade. Trad. Sebastião Nascimento. 2.ed. São Paulo: Editora 34, 2011.

BRANDEIS, Louis D.; WARREN, Samuel D. The right to privacy. Harvard Law Review, vol. 4, n. 5, Cambridge, dez. 1890, p. 193-220. Disponível em: https://www.cs.cornell.edu/ shmat/courses/cs5436/warren-brandeis.pdf. Acesso: 10 jun. 2020.

BOBBIO, Norberto. Teoria do Ordenamento Jurídico. Brasília: Editora UnB, 1982.

CAPANEMA, Walter Aranha. A responsabilidade civil na Lei Geral de Proteção de Dados. Cadernos Jurídicos: Direito Digital e proteção de dados pessoais, ano 21, n. 53, São Paulo,jan./mar. 2020, p. 163-170.

CASTELLS, Manuel. La Galáxia internet. Madrid: Areté, 2001.

CANARIS, Claus-Wilhelm. Pensamento Sistemático e Conceito de Sistema na Ciência do Direito. Lisboa: Calouste Gulbenkian, 1996.

COSTA NETO, Moacyr da. A autonomia privada e a prevalência do negociado. Revista Univap, v. 24, n. 45, Edição especial, São José dos Campos, 2018. p. 61-69. 
DEVLIN, Alan. Principles of law and economics. Routledge: Nova York, 2015.

ERICKSON, Abigayle. Comparative Analysis of the EU's GDPR and Brazil's LGPD: Enforcement Challenges with the LGPD, Brooklyn Journal of International Law, v. 44, n. 2, New York, 2019, Disponível em: https://brooklynworks.brooklaw.edu/bjil/vol44/iss2/9. Acesso em: 10 jun. 2020.

FACHIN, Luiz Edson. "Virada de Copérnico": um convite à reflexão sobre o direito civil brasileiro contemporâneo. In: FACHIN, Luiz Edson (coord.). Repensando fundamentos do direito civil brasileiro contemporâneo. Rio de Janeiro: Renovar, 1998. p. 317-324.

FINKELSTEIN, Maria Eugenia; FINKELSTEIN, Cláudio. Privacidade e lei geral de proteção de dados pessoais. Revista de Direito Brasileira, v. 23, n. 9, Florianópolis, mai./ago. 2019, p. 284-301.

FRAZÃO, Ana. Fundamentos da proteção dos dados pessoais: Noções introdutórias para a compreensão da importância da Lei Geral de Proteção de Dados. In: FRAZÃO Ana; TEPEDINO, Gustavo; OLIVA, Milena Donato (coord.). A lei geral de proteção de dados pessoais e suas repercussões no direito brasileiro. São Paulo: Thomson Reuters, 2019. p. 23-52.

LEMINSKI, Paulo. Novas tendências da responsabilidade civil brasileira. In: SCHREIBER, Anderson (Coord.). Direito civil e constituição. São Paulo: Atlas, 2013. p. 149-172.

LISBOA, Roberto Senise. Boa-fé e confiança na Lei Geral de Proteção de Dados brasileira. Revista do Advogado, n. 144, São Paulo, 2019, p. 6-11.

LOPEZ, Tereza Ancona. Responsabilidade civil na sociedade do risco. Revista da Faculdade de Direito da Universidade de São Paulo, v. 105, São Paulo, jan./dez. 2010. p. 1223-1234.

MORAES, Maria Celina Bodin de. LGPD: um novo regime de responsabilização civil dito "proativo". Revista Civilistica, ano 8, n. 3, Rio de Janeiro, 2019. Disponível em: http://civilistica.com/lgpd-um-novo-regime/. Acesso: 27 jun 2020.

POSNER, Richard A. The right of privacy. Georgia Law Review, v. 12, n. 3, Athens, 1978, p. 393-422. Disponível em: https://chicagounbound.uchicago.edu/cgi/viewcontent.cgi?article=2803\&context=journal_arti cles. Acesso em 10 jun. 2020.

SCHREIBER, Anderson. Novos paradigmas da responsabilidade civil: da erosão dos filtros à diluição dos danos. 2.ed. São Paulo: Atlas, 2009.

SOLOVE, Daniel J. A taxonomy of privacy. University of Pennsylvania Law Review, v. 157, n. 3, Philadelphia, jan. 2006. p. 477-560.

STAJN, Rachel. Sistema financeiro. Rio de Janeiro: Elsevier, 2011.

TASSO, Fernando Antonio. A responsabilidade civil na Lei Geral de Proteção de Dados e sua interface com o Código Civil e o Código de Defesa do Consumidor. Cadernos Jurídicos: Direito Digital e proteção de dados pessoais, São Paulo, ano 21, n. 53, São Paulo, jan./mar. 2020, p. 97-116.

TEFFÉ, Chiara Spadaccini de; VIOLA, Mario. Tratamento de dados pessoais na LGPD: estudo sobre as bases legais. Revista Civilistica, ano 9, n. 1, Rio de Janeiro, 2020, p. 1-38. CONPEDI LAW REVIEW | EVENTO VIRTUAL | v. 6 | n. 1 | p. 158 - 174 | JAN - DEZ | 2020 
Disponível em: http://civilistica.com/tratamento-de-dados-pessoais-na-lgpd/. Acesso em 10 jun. 2020.

TEPEDINO, Gustavo; SILVA, Rodrigo da Guia. Desafios da inteligência artificial em matéria de responsabilidade civil. Revista Brasileira de Direito Civil - RBDCivil, v. 21, Belo Horizonte, jul./set. 2019, p. 61-86. 